\title{
Reduced adiposity in bitter melon (Momordica charantia) fed rats is associated with lower tissue triglyceride and higher plasma catecholamines
}

\author{
Qixuan Chen and Edmund T. S. Li* \\ Food and Nutritional Science Program, Department of Zoology, University of Hong Kong, Pokfulam, Hong Kong SAR, \\ The People's Republic of China \\ (Received 29 April 2004 - Revised 18 October 2004 - Accepted 7 December 2004)
}

\begin{abstract}
Slower weight gain and less visceral fat had been observed when rats fed a high-fat diet were supplemented with freeze-dried bitter melon (BM) juice; the metabolic consequences and possible mechanism(s) were further explored in the present study. In a 4-week experiment, rats were fed a low-fat (70 g/kg) or a high-fat $(300 \mathrm{~g} / \mathrm{kg})$ diet with or without BM $(7.5 \mathrm{~g} / \mathrm{kg}$ or $0.75 \%)$. BM-supplemented rats had lower energy efficiency, visceral fat mass, plasma glucose and hepatic triacylglycerol, but higher serum free fatty acids and plasma catecholamines. In the second experiment, 7-week BM supplementation in high-fat diet rats led to a lowering of hepatic triacylglycerol $(P<0.05)$ and steatosis score $(P<0.05)$ similar to those in rats fed a low-fat diet. BM supplementation did not affect serum and hepatic cholesterol. However, plasma epinephrine and serum free fatty acid concentrations were increased $(P<0 \cdot 05)$. In the third experiment, $\mathrm{BM}(7.5$ and $15 \mathrm{~g} / \mathrm{kg})$ and $1.5 \% \mathrm{BM}$ lowered triacylglycerol concentration in red gastrocnemius and tibialis anterior $(P<0 \cdot 05)$ muscle, but a doseresponse effect was not observed. These data suggest that chronic BM feeding leads to a general decrease in tissue fat accumulation and that such an effect is mediated in part by enhanced sympathetic activity and lipolysis. BM or its bioactive ingredient(s) could be used as a dietary adjunct in the control of body weight and blood glucose.
\end{abstract}

Bitter melon: Adiposity: Triacylglycerol: Catecholamines

Diabetes represents a major public health concern, and its prevalence continues to escalate worldwide (Mokdad et al. 2003). A large proportion of diabetics do use herbs and other dietary supplements as adjuncts to traditional treatments (Yeh et al. 2003). Bitter melon (Momordica charantia, BM), as the most popular plant used by diabetics (Marles \& Farnsworth, 1995), is widely grown in tropical areas. The efficacy and safety of BM have been the subject of several recent reviews (Raman \& Lau, 1996; Shapiro \& Gong, 2002; Basch et al. 2003; Yeh et al. 2003; Grover \& Yadav, 2004). Despite the need for more information in randomised controlled trails, BM-induced decreases in blood glucose appear to be a recognised effect, and no serious adverse effects on humans have been reported. Since the blood glucose-lowering effect is demonstrable with a single oral dose, the acute effect has been attributed to the presence of an insulin-like polypeptide in BM (Khanna et al. 1981), a decrease in glucose absorption (Meir \& Yaniv, 1985) or an increase in hepatic glucose utilisation (Shibib et al. 1993). The mechanisms of actions of $\mathrm{BM}$ to lower blood glucose remain inconclusive. Longer-term studies, however, reveal additional potential health benefits of BM.

In our recent study (Chen et al. 2003), chronic BM supplementation not only improved glucose tolerance and lowered plasma glucose, but also reduced visceral fat mass and energy efficiency (EE) in rats fed a high-fat (HF) diet. As the latter observations are not attributable to decreases in energy intake or apparent fat absorption, some effects on lipid metabolism were suggested.
The effects of BM feeding on plasma lipids in rats have been reported in normal and chemically induced diabetic rats, with mixed results (Singh et al. 1989; Platel et al. 1993; Jayasooriya et al. 2000; Ahmed et al. 2001; Virdi et al. 2003). Given that the plasma free fatty acid (FFA) concentration was elevated in rats fed the BM-supplemented HF diet (Chen et al. 2003), the objectives of the present study were to determine whether a reduced fat content in tissues is a general phenomenon and to begin to search for further evidence of an enhanced lipolysis by monitoring sympathetic activity. Accordingly, the triacylglycerol (TG) contents of major organs involved in insulin resistance, and plasma catecholamines, were determined in a series of three separate experiments.

\section{Materials and methods \\ Freeze-dried bitter melon juice and experimental diets}

Procedures described previously were followed (Chen et al. 2003). Unripe BM fresh fruits were purchased from a local market. Seeds were removed and juice was extracted using an electric juicer. After $72 \mathrm{~h}$ of freeze-drying, the yield was about $16 \mathrm{~g}$ powder per kilogram fresh fruit. The $\mathrm{BM}$ powder was kept in airtight containers at $-70^{\circ} \mathrm{C}$ until use.

The formulation of the powder diets was based on the AIN-93G recommendation (American Institute of Nutrition, 1993). The low fat (LF) diet contained $70 \mathrm{~g}$ fat $/ \mathrm{kg}$ diet. The HF diet $(300 \mathrm{~g}$ fat $/ \mathrm{kg}$ 
diet) was obtained by adding Crisco shortening (Procter \& Gamble, Cincinatti, OH, USA), at the expense of cornstarch. The freeze-dried BM juice powder was also added at the expense of cornstarch (Table 1).

\section{Animals}

All animal protocols were approved by the Committee on the Use of Live Animals in Teaching and Research at The University of Hong Kong. The procedures were performed in accordance with the NIH Guide for the Care and Use of Laboratory Animals (National Institutes of Health, 1996). Rats were obtained, at 6 weeks of age, from the existing colony in the animal unit of the Medicine Faculty. They were housed individually in rectangular, hanging wire cages in an environmentally controlled room $\left(12 \mathrm{~h}\right.$ cycle with lights on at $\left.07.00 \mathrm{~h} ; 22 \pm 2^{\circ} \mathrm{C}\right)$. The rats were given free access to water and consumed laboratory food (Lab Diet - The Richmond Standard; PMI Nutrition International Inc., St Louis, MO, USA) until they were assigned to individual groups. The rats were weighed twice a week. Food cup and spillage were weighed daily, and reported intakes were corrected for spillage. At the end of an experiment, rats that had been fooddeprived for $8 \mathrm{~h}$ were killed by decapitation. Blood was collected; serum and plasma were stored at $-70^{\circ} \mathrm{C}$. Liver, visceral fat (Chen et al. 2003), tibialis anterior and the red medial part of gastrocnemius (Franch et al. 2002) were excised, frozen and stored in liquid $\mathrm{N}_{2}$ until analysis.

Three experiments were conducted. In experiment $1, \mathrm{BM}$ and $\mathrm{HF}$ were introduced to the rats at the beginning. In order to assess the impact of BM supplementation on overweight rats, male rats were pre-exposed to an HF diet for 4 weeks in experiment 2. The experiment was also designed to compare the effect of BM supplementation on the HF-diet rats with those switched from an HF to an LF diet. In the last experiment, female rats were used with the assumption that if BM affects body weight, the effect might be better demonstrated in slow-growing adult females.

Experiment 1. Male Sprague-Dawley rats (170-190g, $n$ 32) were randomly assigned to one of four dietary groups. They were fed one of the following diets for 4 weeks (Table 1): LF; $\mathrm{LF}+\mathrm{BM}(0.75 \%, \mathrm{w} / \mathrm{w}) ; \mathrm{HF}$; or HF $+\mathrm{BM}(0.75 \%, \mathrm{w} / \mathrm{w})$.

Experiment 2. Male Sprague-Dawley rats $(170-190 \mathrm{~g})$ were fed an LF ( $n$ 7) or HF ( $n$ 32) diet. Beginning at week 5, the HF rats were randomly assigned to one of the four diets for 7 weeks (Table 1): $\mathrm{HF}, \mathrm{HF}+0.75 \% \mathrm{BM}(\mathrm{HF} / \mathrm{HF}+\mathrm{BM}), \mathrm{LF}$ $(\mathrm{HF} / \mathrm{LF})$ and $\mathrm{LF}+0.75 \% \mathrm{BM}(\mathrm{HF} / \mathrm{LF}+\mathrm{BM})$.

Experiment 3. Female Sprague-Dawley rats (140-160g) were fed an LF $(n 5)$ or HF ( $n$ 25) diet for 6 weeks. At the beginning of week 7 , some HF rats continued to receive the HF diet (HF, $n$ 8) while the others were switched to an $\mathrm{HF}+0.75 \%$ $\mathrm{BM}(n)$ ) or $\mathrm{HF}+1.5 \% \mathrm{BM}(n)$ diet for 9 weeks.

\section{Measurements}

Plasma glucose was assayed immediately using a commercially available glucose oxidase kit (Kit No. 510-A; Sigma Chemical Co., St Louis, MO, USA). Serum FFA level was determined by an enzymatic colorimetric assay (NEFA C test kit; Wako, Osaka, Japan). Serum insulin was determined by ELISA (Mercodia rat insulin 10-1124-01; Mercordia AB, Uppsala, Sweden).

Serum TG was measured enzymatically (GPO-HDAOS method, L-Type TG-H kit; Wako). With this method, free glycerol was removed in a reaction prior to the hydrolysis of TG and colour development. Serum total cholesterol was determined by a cholesterol oxidase-HDAOS method (L-Type CHO-H kit; Wako). Lipids in liver and muscles were first extracted with a mixture of chloroform and methanol (Folch et al. 1957). Lipids were dissolved in tert-butyl alcohol, and Triton X-100-methanol $(1: 1$,$) was added before enzymatic assays for TG and cholesterol,$ were carried out (Danno et al. 1992).

For plasma catecholamines, a portion of the blood was collected in chilled lithium heparin tubes containing $50 \mu l$ of a mixture of EDTA and glutathione $(4.75 \mathrm{~g}$ EDTA and $3.00 \mathrm{~g}$ glutathione dissolved in $50 \mathrm{ml}$ double-distilled deionised water and the $\mathrm{pH}$ adjusted to 6.8; Forster \& Macdonold, 1999). Plasma epinephrine and norepinephrine were measured by reverse-phase liquid chromatography with electrochemical detection. Plasma epinephrine and norepinephrine were extracted with

Table 1. Composition of experimental diets*

\begin{tabular}{|c|c|c|c|c|c|}
\hline & \multicolumn{2}{|c|}{ Low-fat diet (LF) } & \multicolumn{3}{|c|}{ High-fat diet (HF) } \\
\hline & LF & $\mathrm{LF}+0.75 \% \mathrm{BM}$ & $\mathrm{HF}$ & $\mathrm{HF}+0.75 \% \mathrm{BM}$ & $\mathrm{HF}+1.5 \% \mathrm{BM}$ \\
\hline Casein $(g / k g) \dagger$ & $200 \cdot 0$ & $200 \cdot 0$ & $255 \cdot 0$ & $255 \cdot 0$ & $255 \cdot 0$ \\
\hline Cornstarch $(\mathrm{g} / \mathrm{kg}) \dagger$ & $529 \cdot 5$ & $522 \cdot 0$ & 231.5 & $224 \cdot 0$ & $216 \cdot 5$ \\
\hline Sucrose $(\mathrm{g} / \mathrm{kg}) \dagger$ & $100 \cdot 0$ & $100 \cdot 0$ & $100 \cdot 0$ & $100 \cdot 0$ & $100 \cdot 0$ \\
\hline Cellulose (fibre) $(\mathrm{g} / \mathrm{kg}) \dagger$ & $50 \cdot 0$ & $50 \cdot 0$ & $50 \cdot 0$ & $50 \cdot 0$ & $50 \cdot 0$ \\
\hline Corn oil $(\mathrm{g} / \mathrm{kg}) \ddagger$ & $70 \cdot 0$ & $70 \cdot 0$ & $70 \cdot 0$ & $70 \cdot 0$ & $70 \cdot 0$ \\
\hline Shortening $(\mathrm{g} / \mathrm{kg}) \ddagger$ & 0 & 0 & $230 \cdot 0$ & $230 \cdot 0$ & $230 \cdot 0$ \\
\hline Mineral mix $(\mathrm{g} / \mathrm{kg}) \dagger$ & $35 \cdot 0$ & $35 \cdot 0$ & $45 \cdot 0$ & $45 \cdot 0$ & $45 \cdot 0$ \\
\hline Vitamin mix $(\mathrm{g} / \mathrm{kg}) \dagger$ & $10 \cdot 0$ & $10 \cdot 0$ & $13 \cdot 0$ & $13 \cdot 0$ & $13 \cdot 0$ \\
\hline Miscellaneous $(\mathrm{g} / \mathrm{kg}) \S$ & $5 \cdot 514$ & $5 \cdot 514$ & $5 \cdot 514$ & $5 \cdot 514$ & $5 \cdot 514$ \\
\hline Bitter melon $(\mathrm{BM})(\mathrm{g} / \mathrm{kg}) \|$ & 0 & 7.5 & 0 & 7.5 & $15 \cdot 0$ \\
\hline Energy density (MJ/kg) ๆ & $16 \cdot 44$ & $16 \cdot 32$ & 21.01 & $20 \cdot 88$ & $20 \cdot 76$ \\
\hline
\end{tabular}

*Based on the AIN-93G diet (American Institute of Nutrition, 1993).

† Harlan Teklad (Madison, WI, USA).

¥ Mazola corn oil (CPC Int., Malaysia); Crisco shortening: Partially hydrogenated vegetable shortening from Procter \& Gamble Co. (Cincinatti, OH, USA)

§ Choline bitartrate $(2.5 \mathrm{~g} / \mathrm{kg})$, L-cystine $(3.0 \mathrm{~g} / \mathrm{kg})$ and tert-butylhydroquinone $(0.014 \mathrm{~g} / \mathrm{kg})$.

$\|$ Added as freeze-dried bitter melon juice (BM).

ๆ Based on Atwater factors: $16.74 \mathrm{MJ} / \mathrm{kg}$ for protein and carbohydrates, $37.66 \mathrm{MJ} / \mathrm{kg}$ for fat. 
acid-washed alumina (type WA-4; Sigma Chemicals) and desorbed with acetic acid buffer. 3,4-Dihydroxybenzylamine hydrobromide was used as an internal standard. Samples were injected into an HPLC system. The mobile phase $(200 \mathrm{ml}$ methanol, $9.02 \mathrm{~g}$ sodium acetate, $0.372 \mathrm{~g}$ disodium EDTA and $100 \mathrm{mg}$ sodium dodecyl sulphate dissolved in $1000 \mathrm{ml}$ deionised water, pH 5.1) was pumped (PM-80, Bioanalytical Systems, West Lafayette, IN, USA) through a $3 \mu \mathrm{m}$ octadecylsilane column (PHASEII, Part No. MF 6213, $100 \times 3.2 \mathrm{~mm}$; Bioanalytical Systems) at a rate of $0.7 \mathrm{ml} / \mathrm{min}$. A dual glass carbon electrode was connected to an amperometric detector (LC-4C; Bioanalytical Systems). The potential was set at $+0.85 \mathrm{~V}$ with an $\mathrm{Ag} / \mathrm{AgCl}$ reference electrode. The detector range was set at $0 \cdot 1 \mu \mathrm{A}$. Peaks were quantified by area (Allchrom software; Alltech Association Inc., Deerfield, IL, USA). The within-assay CV was $3.8 \%$ and $5.6 \%$ for epinephrine and norepinephrine, respectively. The between-assay CV was $9.9 \%$ for epinephrine and $8.1 \%$ for norepinephrine. Recovery was $92.4 \%$ for epinephrine and $91.7 \%$ for norepinephrine.

\section{Liver histology}

The right lobe of the liver from each rat was fixed overnight in $10 \%$ buffered formalin solution and embedded in paraffin. Histological sections $(4 \mu \mathrm{m})$ were prepared and stained with haematoxylin-eosin. Three sections $(12 \mu \mathrm{m}$ apart) from each rat were graded blindly. A score of 0 to 3 was used to describe the extent of steatosis (Hourigan et al. 1999; Friedenberg et al. 2003). A zero score represents normal liver structure in which lipid accumulation in the hepatocytes is not observed. A score of 1 depicts mild lipid infiltration (occurring in $<30 \%$ hepatocytes), a score of 2 depicts moderate lipid infiltration (occurring in $30-70 \%$ hepatocytes), whereas a score of 3 indicates severe lipid infiltration (occurring in $>70 \%$ of hepatocytes). In addition, the presence or absence of liver cell injury, including inflammation, fibrosis and necrosis, was also noted.

\section{Statistical methods}

Data are expressed as means with their standard errors. Analyses were carried out with the Statistical Package for the Social Science (SPSS for Windows, version 10.1; Chicago, IL, USA). In experiment 1, two-way ANOVA was used to examine the effects of dietary fat (two levels: LF and HF), BM (two levels: with and without $\mathrm{BM}$ ) and their interactions. In experiments 2 and 3, data were analysed by one-way ANOVA followed by post hoc Duncan's multiple range tests to determine treatment effect and compare differences among group means. Univariate analysis was also carried out to control for differences in energy intake. A non-parametric Kruskal-Wallis test was employed to determine the effect of dietary manipulations on steatosis score. When the scores between two groups were compared, the Mann-Whitney test was applied. Correlation analysis was performed to determine the relationship between two variables. Statistical significance was accepted at $P<0.05$.

\section{Results}

\section{Weight gain and energy intake}

In experiment 1 , significant effects of dietary fat and BM on weight gain and EE were observed (Table 2). Rats fed an HFdiet consumed more energy. However, BM supplementation did not affect the energy intake of rats. The weight gain of rats given BM was $6.9 \%$ and $9.4 \%$ less than that of their respective LF and HF controls. As a result, BM supplementation led to a reduction in $\mathrm{EE}(P<0.05)$.

The growth and EE data for rats in experiment 2 have been reported (Chen et al. 2003; marked with $\ddagger$ in Table 4). Rats in the $\mathrm{HF} / \mathrm{HF}+\mathrm{BM}$ group gained less weight and had a lower EE than the HF group $(P<0 \cdot 05)$. The HF/LF or HF/LF + BM rats all gained less weight and had a lower EE (over 7 weeks, $P<0.05)$ than rats fed an LF-diet for the entire study period.

In experiment $3, \mathrm{EE}$ progressively decreased with increase in $\mathrm{BM}(4.6,3.3$ and 2.8 for $\mathrm{HF}, \mathrm{HF}+0.75 \% \mathrm{BM}$ and $\mathrm{HF}+1.5 \%$ $\mathrm{BM}$, respectively). Weight gain for the three groups over a period of 9 weeks was 124,78 and $67 \mathrm{~g}$ respectively.

\section{Glucose, insulin, free fatty acids and visceral fat mass}

In experiment 1 , the final concentration of plasma glucose was higher in rats fed an HF diet than in rats fed an LF diet (Table 3; $P<0 \cdot 05$ ). BM supplementation normalised plasma glucose $(P<0 \cdot 05)$. However, serum insulin concentration and insulin resistance index were similar among the four groups.

There were dietary fat and BM effects on serum FFA and visceral fat mass (Table $3 ; P<0.05$ ). As dietary fat content increased, serum FFA concentration decreased. In contrast, BM supplementation increased serum FFA concentration. As expected, HF feeding elevated visceral fat mass, whereas BM supplementation lowered visceral fat accumulation. Among the rats in experiment 1, visceral fat mass correlated negatively with serum FFA ( $r-0.61, n 32, P 0.001)$ but positively with plasma glucose $(r=0.48, n 32, P=0.006)$.

Table 2. Growth and feed intake of male rats after 4 weeks of bitter melon (BM) supplementation (experiment 1 ) (Male rats given a low-fat diet (LF) LF $+0.75 \%$ $\mathrm{BM}$, high-fat diet (HF) or HF $+0.75 \%$ BM for 4 weeks)

\begin{tabular}{|c|c|c|c|c|c|c|c|c|c|c|c|}
\hline & \multicolumn{2}{|c|}{ LF } & \multicolumn{2}{|c|}{$\mathrm{LF}+0.75 \% \mathrm{BM}$} & \multicolumn{2}{|c|}{ HF } & \multicolumn{2}{|c|}{$\mathrm{HF}+0.75 \% \mathrm{BM}$} & \multicolumn{3}{|c|}{$P$ value (two-way ANOVA) } \\
\hline & Mean & SE & Mean & SE & Mean & SE & Mean & SE & Fat & BM & Fat $\times \mathrm{BM}$ \\
\hline Initial body weight (g) & 186 & 2 & 187 & 3 & 184 & 3 & 186 & 3 & & & \\
\hline Body weight at week 4 (g) & 446 & 6 & 430 & 13 & 492 & 10 & 465 & 6 & 0.001 & 0.031 & 0.584 \\
\hline Weight gain (g/4 weeks) & 260 & 6 & 242 & 12 & 308 & 8 & 279 & 5 & 0.01 & 0.011 & 0.520 \\
\hline Energy intake (MJ/4 weeks) & $14 \cdot 8$ & 0.4 & $14 \cdot 5$ & 0.4 & $15 \cdot 9$ & 0.6 & $15 \cdot 7$ & 0.3 & 0.015 & 0.595 & 0.973 \\
\hline EE (g gain/MJ) & $17 \cdot 6$ & 0.3 & $16 \cdot 7$ & 0.5 & $19 \cdot 4$ & 0.3 & $17 \cdot 8$ & 0.3 & 0.001 & 0.001 & 0.403 \\
\hline
\end{tabular}




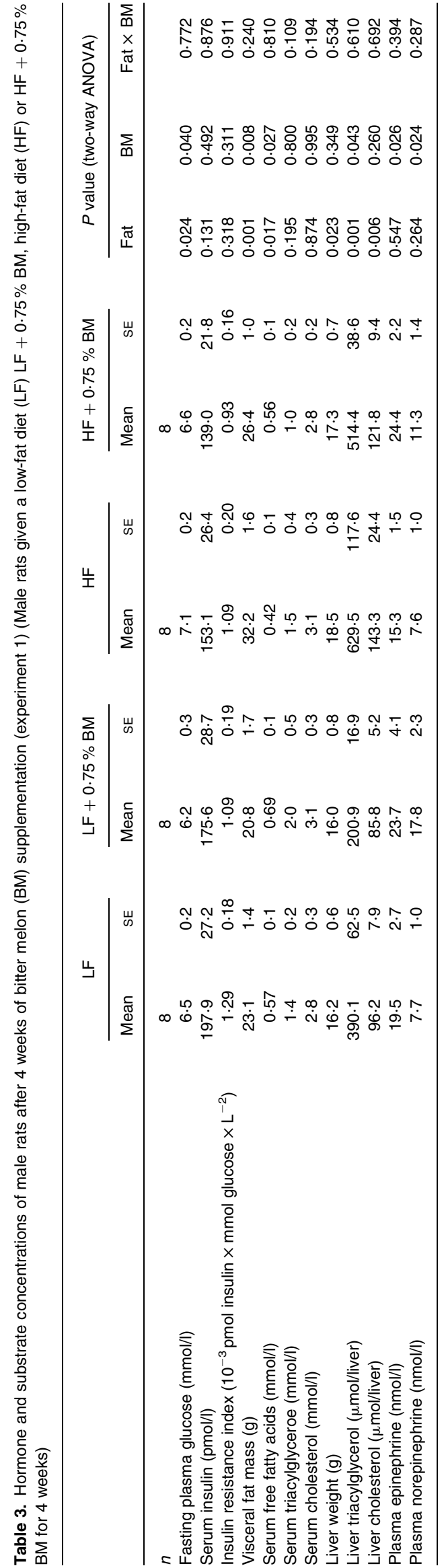

\section{Plasma catecholamines}

In experiment 1, plasma epinephrine and norepinephrine concentrations were increased with BM supplementation (Table 3; $P<0.05)$.

In experiment 2, plasma epinephrine concentration was lower in the HF rats compared with the LF rats (Table $4 ; P<0.05$ ). However, the plasma epinephrine concentration of the $\mathrm{HF} /$ $\mathrm{HF}+\mathrm{BM}$ rats was $44.8 \%$ higher than that in the $\mathrm{HF}$ rats $(P<0.05)$ and was comparable to that of the LF rats. In this experiment, plasma norepinephrine concentration did not differ among groups. Nevertheless, serum FFA was found to correlate positively with both epinephrine $(r 0.34, n 39, P=0.034)$ and norepinephrine $(r 0.33, n 39, P=0.038)$.

Plasma catecholamines were not measured in experiment 3.

\section{Muscle triacylglycerol and cholesterol}

In experiment 3 , the $\mathrm{TG}$ concentration in both red gastrocnemius and tibialis anterior was higher in HF rats than in LF rats (Fig. 1; $P<0.05)$. The addition of BM to the HF-diet lowered TG concentrations in both types of skeletal muscle $(P<0 \cdot 05)$.

In all experiments, muscle cholesterol concentration was not affected by dietary manipulations (data not shown).

\section{Hepatic triacylglycerol, cholesterol and histopathology}

In experiment 1 , feeding an HF-diet led to rats with a greater liver weight, but BM had no impact on liver weight (Table 3). Interestingly, there were effects of dietary fat and BM on hepatic TG content (similar results if based on per gram of liver). The accumulation of TG caused by $\mathrm{HF}$ feeding was reduced by $18 \%$ upon BM supplementation $(P<0.05)$.

In experiment 2 , the $\mathrm{HF} / \mathrm{LF}$ rats and $\mathrm{HF} / \mathrm{HF}+\mathrm{BM}$ rats had a similar hepatic TG content that was $40.5 \%$ and $36.9 \%$ lower than that of the HF rats (Table $4 ; P<0.05$ ).

In experiment 3 , liver weight was no different among the four groups (data not shown). The hepatic TG content of the LF, $\mathrm{HF}+0.75 \% \mathrm{BM}$ and $\mathrm{HF}+1.5 \% \mathrm{BM}$ groups was similar but significantly lower than that of the HF group (Fig. 1).

Steatosis scores on liver sections from the rats of experiments 2 and 3 are shown in Fig. 2. In experiment 2, the HF/LF, HF/ $\mathrm{LF}+\mathrm{BM}$ and $\mathrm{HF} / \mathrm{HF}+\mathrm{BM}$ rats all had steatosis scores that were not different from the LF rats but were lower than the HF rats $(P<0.05)$. In experiment 3 , steatosis scores decreased progressively with $\mathrm{BM}$ supplementation. Scores from the $\mathrm{HF}+1.5 \% \mathrm{BM}$ rats were similar to those of the LF rats but were lower than those of the HF rats $(P<0.05)$.

Photomicrographs of liver sections (experiment 2) characterising the different stages of steatosis are shown in Fig. 3. Fig. 3A represents samples with a score of zero. Over half of the rats fed the LF diet received this score. Rats switched to an LF diet (HF/LF) or fed diets supplemented with varying doses of BM had mild (score of 1; Fig. 3B) to moderate (score of 2; Fig. 3C) macro- and microvesicular steatosis. Macro- and microvesicular steatosis, if present, was predominantly located in the periportal area. As expected, fatty liver was observed in most rats fed an HF diet. These rats had moderate to severe (score of 3; Fig. 3D), mixed micro- and macrovesicular steatosis and even foamy degeneration (Fig. 3E) in the liver. There was no dilatation 
Table 4. Effects of bitter melon (BM) supplementation or low-fat diet (LF) on hormone and substrate concentrations of male rats previously exposed to a high-fat diet (HF) (experiment 2$)^{\star} \dagger$

\begin{tabular}{|c|c|c|c|c|c|c|c|c|c|c|}
\hline & \multicolumn{2}{|c|}{ LF } & \multicolumn{2}{|c|}{ HF/LF } & \multicolumn{2}{|c|}{$\mathrm{HF} / \mathrm{LF}+\mathrm{BM}$} & \multicolumn{2}{|c|}{$\mathrm{HF}$} & \multicolumn{2}{|c|}{$\mathrm{HF} / \mathrm{HF}+\mathrm{BM}$} \\
\hline & Mean & SE & Mean & SE & Mean & SE & Mean & SE & Mean & SE \\
\hline$n$ & 7 & & 8 & & 8 & & 8 & & 8 & \\
\hline Body weight at wk $11(\mathrm{~g}) \ddagger$ & $610^{\mathrm{a}}$ & 22 & $626^{a}$ & 13 & $620^{\mathrm{a}}$ & 12 & $723^{c}$ & 16 & $675^{\mathrm{b}}$ & 17 \\
\hline Weight gain ( $g / 7$ weeks) $\ddagger$ & $175^{\mathrm{b}}$ & 11 & $146^{\mathrm{a}}$ & 10 & $139^{\mathrm{a}}$ & 8 & $235^{\mathrm{c}}$ & 6 & $195^{\mathrm{b}}$ & 7 \\
\hline Energy efficiency (g gain/MJ)‡ & $7 \cdot 0^{\mathrm{b}}$ & 0.3 & $5 \cdot 9^{a}$ & 0.4 & $5 \cdot 9^{\mathrm{a}}$ & 0.6 & $8 \cdot 3^{\mathrm{c}}$ & 0.2 & $7 \cdot 1^{\mathrm{b}}$ & 0.2 \\
\hline Visceral fat weight $(\mathrm{g}) \ddagger$ & $45 \cdot 4^{a}$ & 4.6 & $49 \cdot 9^{a}$ & 3.9 & $46 \cdot 9^{a}$ & $3 \cdot 3$ & $79 \cdot 3^{c}$ & 4.5 & $66 \cdot 9^{b}$ & $4 \cdot 3$ \\
\hline Serum triacylglycerol $(\mathrm{mmol} / \mathrm{l})$ & $2 \cdot 2^{\mathrm{ab}}$ & 0.3 & $3 \cdot 1^{b}$ & 0.4 & $2 \cdot 1^{\mathrm{a}}$ & 0.4 & $2 \cdot 1^{\mathrm{a}}$ & 0.3 & $1.6^{\mathrm{a}}$ & 0.3 \\
\hline Serum cholesterol (mmol/l) & $3 \cdot 7$ & 0.3 & $3 \cdot 8$ & 0.3 & $4 \cdot 0$ & 0.3 & $3 \cdot 7$ & 0.4 & $3 \cdot 4$ & 0.3 \\
\hline Liver weight $(\mathrm{g}) \ddagger$ & $20 \cdot 3^{a}$ & 0.8 & $22 \cdot 1^{\mathrm{ab}}$ & 0.9 & $21 \cdot 3^{a}$ & 0.8 & $24 \cdot 1^{\mathrm{b}}$ & 1.0 & $20 \cdot 9^{a}$ & 0.8 \\
\hline Liver triacylglycerol ( $\mu \mathrm{mol} /$ liver) & $913.8^{\mathrm{a}}$ & $129 \cdot 1$ & $756 \cdot 1^{\mathrm{a}}$ & $129 \cdot 2$ & $573.7^{a}$ & 62.9 & $1270 \cdot 0^{b}$ & $139 \cdot 1$ & $801 \cdot 1^{\mathrm{a}}$ & $137 \cdot 1$ \\
\hline Liver cholesterol ( $\mu \mathrm{mol} /$ liver) & $169 \cdot 6$ & $21 \cdot 3$ & 173.4 & $23 \cdot 9$ & $142 \cdot 3$ & $17 \cdot 2$ & $213 \cdot 7$ & $22 \cdot 7$ & $154 \cdot 2$ & $20 \cdot 8$ \\
\hline Plasma epinephrine (nmol/l) & $64 \cdot 1^{\mathrm{b}}$ & 4.9 & $57 \cdot 8^{\mathrm{ab}}$ & $6 \cdot 0$ & $57 \cdot 1^{\mathrm{ab}}$ & 4.9 & $45 \cdot 5^{\mathrm{a}}$ & 4.6 & $65.9^{b}$ & $4 \cdot 6$ \\
\hline Plasma norepinephrine $(\mathrm{nmol} / \mathrm{l})$ & 29.9 & 2.9 & $31 \cdot 6$ & $7 \cdot 7$ & 33.2 & 3.9 & $32 \cdot 1$ & $3 \cdot 9$ & $42 \cdot 0$ & $5 \cdot 3$ \\
\hline
\end{tabular}

* Male rats were given either an LF diet $(n 7)$ or an HF diet $(n$ 32) for 4 weeks. At the beginning of week 5 , the HF rats were randomly assigned to one of the following groups and fed the respective diets for an additional 7 weeks: $\mathrm{LF}$ fat $(\mathrm{HF} / \mathrm{LF}), \mathrm{LF}+0.75 \% \mathrm{BM}(\mathrm{HF} / \mathrm{LF}+\mathrm{BM}), \mathrm{HF}(\mathrm{HF})$, and $\mathrm{HF}+0.75 \% \mathrm{BM}(\mathrm{HF} / \mathrm{HF}+\mathrm{BM})$. † Covariance: total energy intake. Means in a row not sharing a superscript letter are significantly different, $P<0.05$. $\ddagger$ Data from Chen et al. (2003).

and congestion in the central veins and in the surrounding sinusoids, and no fibrosis and necrosis in any section.

In all experiments, BM supplementation had no effect on serum TG or serum or hepatic cholesterol concentration.

\section{Discussion}

Supplementation with BM slows weight gain and improves insulin sensitivity in rats fed an HF diet. The present results extend our previous study to indicate that the chronic consumption of $\mathrm{BM}$ leads to a general decrease in the TG content of the major organs. Elevated plasma catecholamines and serum FFA suggest an enhanced sympathetic activity and lipolytic process. These data are consistent with the view that bioactive ingredients in $\mathrm{BM}$ possess anti-obesity properties that might be beneficial to body weight and glycaemic control.

In BM rats, a lower adipose tissue mass did not lead to lipid deposition in other major organs. In fact, BM-supplemented rats had less TG in their livers (Tables 3 and 4, Fig. 1) and skeletal muscle (Fig. 1). This generalised reduction in lipid deposition in the major organs suggests interferences of intermediary metabolism by ingredients present in BM. Rats fed an HF diet have dampened fatty acid synthesis (Romsos \& Leveille, 1974), and dietary fatty acids in chylomicrons are taken up by peripheral tissues first before arriving at the liver. Thus, the lower visceral fat and hepatic TG content observed in BM-supplemented rats could be attributable to a decrease in peripheral clearance and enhanced utilisation, respectively. As insulin promotes fat deposition by stimulating lipoprotein lipase (Robinson \& Speake, 1989), positive correlations between the insulin resistance index and visceral fat mass in experiment $2(r 0.653, n 39, P=0.001)$ and experiment 3 ( $r 0.847, n 30, P=0.001)$ do not support an effect involving decreased peripheral uptake. However, a suppressive effect on de novo fatty acid synthesis could not be ruled out because $\mathrm{LF}+\mathrm{BM}$ rats had $10 \%$ less visceral fat and $48.5 \%$ less hepatic TG than LF rats (Table 3).

The elevated concentration of plasma catecholamines is an original observation. Plasma norepinephrine is released from sympathetic nerve endings, and plasma epinephrine is secreted by chromaffin cells of the adrenal medulla. A catecholamine-mediated lipolytic process in BM rats is supported by the positive correlations between serum FFA and plasma catecholamines (see Results). As the decline in weight gain is associated with an enhanced sympathetic activity, the impact of BM on metabolism is reminiscent of that of green tea. Catechin in green tea has been implicated in playing a role in promoting thermogenesis via sympathetic activation (Dulloo et al. 2000). Although BM is not known to contain catechin, it is rich in $\alpha$-eleostearic acid (Yuwai et al. 1991; Suzuki et al. 2001), a conjugated linolenic acid that could give rise to conjugated linoleic acid (Tsuzuki et al. 2003). The latter has been shown to enhance sympathetic activity (Ohnuki et al. 2001). Although unlikely, the possibility that sympathetic activation is the consequence of a stress response cannot be ruled out. Activation of the hypothalamo-pituitary-adrenal axis will lead to the secretion of glucocorticoid. This hormone is known to antagonise the effects of insulin and promote lipolysis. Because the overall effects of BM supplementation are improved glucose tolerance (Chen et al. 2003) and insulin sensitivity (Table 3), an active role for glucocorticoid in mediating the effects of BM is doubtful.

Blood FFA concentration is determined by lipolytic activity as well as by the rate of uptake by tissues for oxidation or re-esterification. Liver is a key site of metabolic integration. The results of experiments 2 and 3 clearly demonstrated the ability of BM supplementation to reverse steatosis and normalise hepatic TG content. In 7 weeks, the hepatic TG level was reduced by $37 \%$ and $40.5 \%$ when rats switched from an $\mathrm{HF}$ to an $\mathrm{HF}+\mathrm{BM}$ or LF diet (experiment 2). In other words, the addition of BM to an HF diet produced effects similar to those of an LF diet. The lowering of hepatic TG is not limited to rats fed HF diets. Rats given a LF diet with (Table 4) or without (Table 3) prior exposure to an HF diet also had a lower hepatic TG upon BM supplementation. This effect is in general agreement with that reported by others who gave BM pulp (Jayasooriya et al. 2000) or juice (Ahmed et al. 2001) to rats fed an LF diet. The anti-fatty liver effect of BM may be of clinical interest as diseases such as diabetes, alcoholism and hepatitis can cause steatosis.

The lower TG content of the skeletal muscle of BMsupplemented rats is another important and original observation 

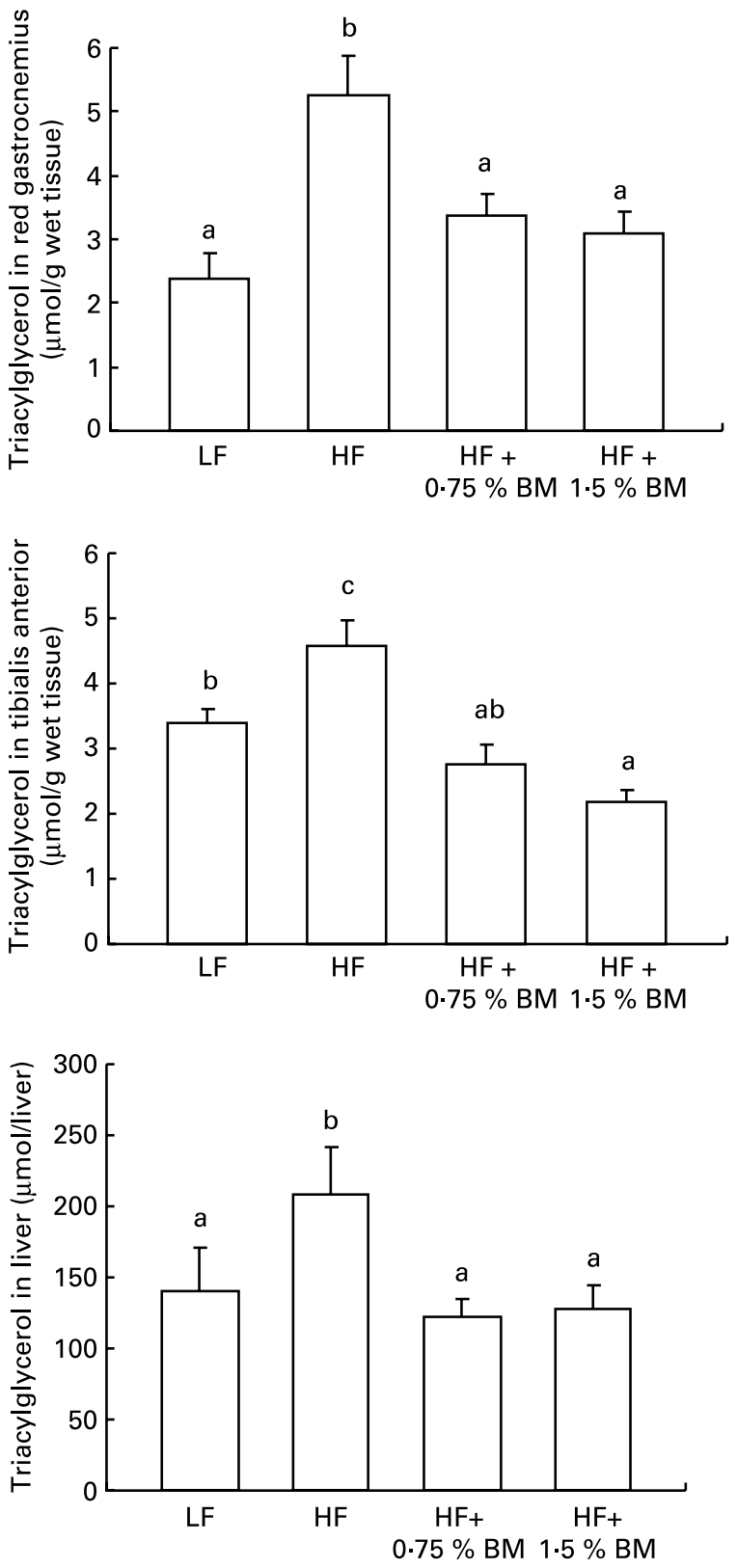

Fig. 1. Triacylglycerol content in the muscle and liver of female rats fed a high-fat diet supplemented with bitter melon (BM) (experiment 3). Rats were given either a low-fat (LF; $n 5$ ) or a high-fat (HF; $n$ 25) diet for 6 weeks. For the following 9 weeks, some of the HF rats were given BM $(0.75 \%$ or $1.5 \%)$ supplementation. Values are means with their standard errors represented by vertical bars. (n 5-9 rats). Univariate analysis with energy intake as covariate was performed. Mean values not sharing the same letters are significantly different $(P<0.05$; post hoc Duncan's multiple range test).

not previously reported. Skeletal muscle is an important metabolic organ that is responsible for $40-50 \%$ of total FFA disposal (Jensen, 2003). Thus, it is generally considered to be the most important site of insulin resistance (Kelley et al. 2002; Hegarty et al. 2003). The present results showed that BM supplementation decreased TG content in the oxidative-type (Peters et al. 2001) red gastrocnemius and tibialis anterior muscles (experiment 3; Fig. 1). At a dose of $0.75 \% \mathrm{BM}$, TG content was lower than in the unsupplemented HF group and similar to that of the LF group. A dose-response effect was observed for tibialis anterior
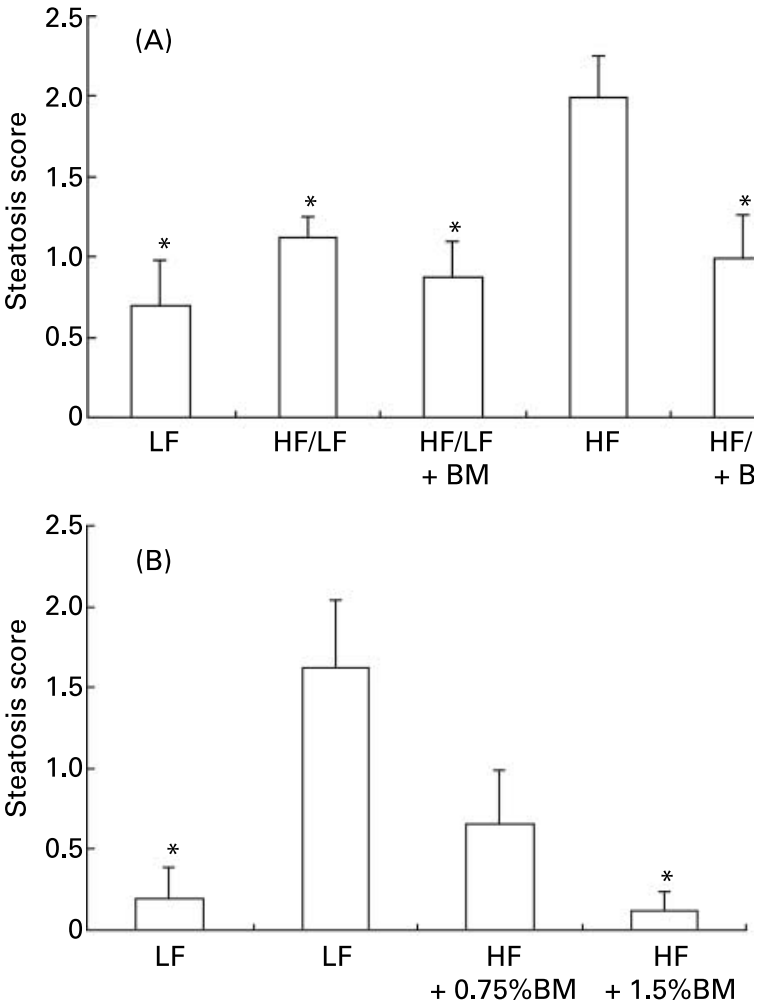

Fig. 2. Histopathological evaluation in the liver of rats. Each section was ranked blindly as described in Materials and methods. In experiment 2 (A), male rats were given either a low-fat (LF) or a high-fat (HF) diet for 4 weeks. At the beginning of week 5 , the $\mathrm{HF}$ rats were randomly assigned to one of the following groups and fed the respective diets for an additional 7 weeks: low fat $(\mathrm{HF} / \mathrm{LF}), \mathrm{LF}+7.5 \mathrm{~g} / \mathrm{kg} \mathrm{BM}(\mathrm{HF} / \mathrm{LF}+\mathrm{BM}), \mathrm{HF}(\mathrm{HF})$ and $\mathrm{HF}+7.5 \mathrm{~g} / \mathrm{kg}$ $\mathrm{BM}(\mathrm{HF} / \mathrm{HF}+\mathrm{BM})$. In experiment $3(\mathrm{~B})$, female rats were used (refer to Fig. 1 for experimental conditions). Values are means with their standard errors represented by vertical bars. (n 5-9 rats). The overall significance of the steatosis score was determined by the non-parametric Kruskal-Wallis test. ${ }^{\star} P<0.05 v$. HF group (Mann-Whitney test).

but not for red gastrocnemius. The reduction of TG within muscles may result from a decreased uptake of fatty acids or from an increased capacity for lipid oxidation. The present data suggest that increased lipid oxidation may be responsible, at least in part, for the reduction of muscle TG in BM rats. The significance of the latter phenomenon is further illustrated by a positive correlation between red gastrocnemius TG concentration and insulin resistance index $(r 0.652, n 30, P=0.001)$.

A lack of effect of BM on serum and tissue cholesterol is consistent with that reported by Virdi et al. (2003) and Jayasooriya et al. (2000) but at variance with that of Platel et al. (1993) and Singh et al. (1989). The reasons for these discrepant results are not apparent and might be related to factors such as the strain of rat, the presence of diabetes, the BM extract preparation method and the duration of treatment.

The mechanisms whereby BM triggers a series of physiological responses resulting in reduced body fat content and improved insulin sensitivity remain to be elucidated. One consistent finding in our experiments was that of an elevated serum FFA in BM-supplemented rats. Because these rats actually had less tissue TG and better glucose tolerance (Chen et al. 2003), the data do not support the general view that FFA induces insulin resistance (Boden et al. 2002). It is speculated that, as ligands of peroxisome proliferator-activated receptors, FFA might promote $\beta$-oxidation 

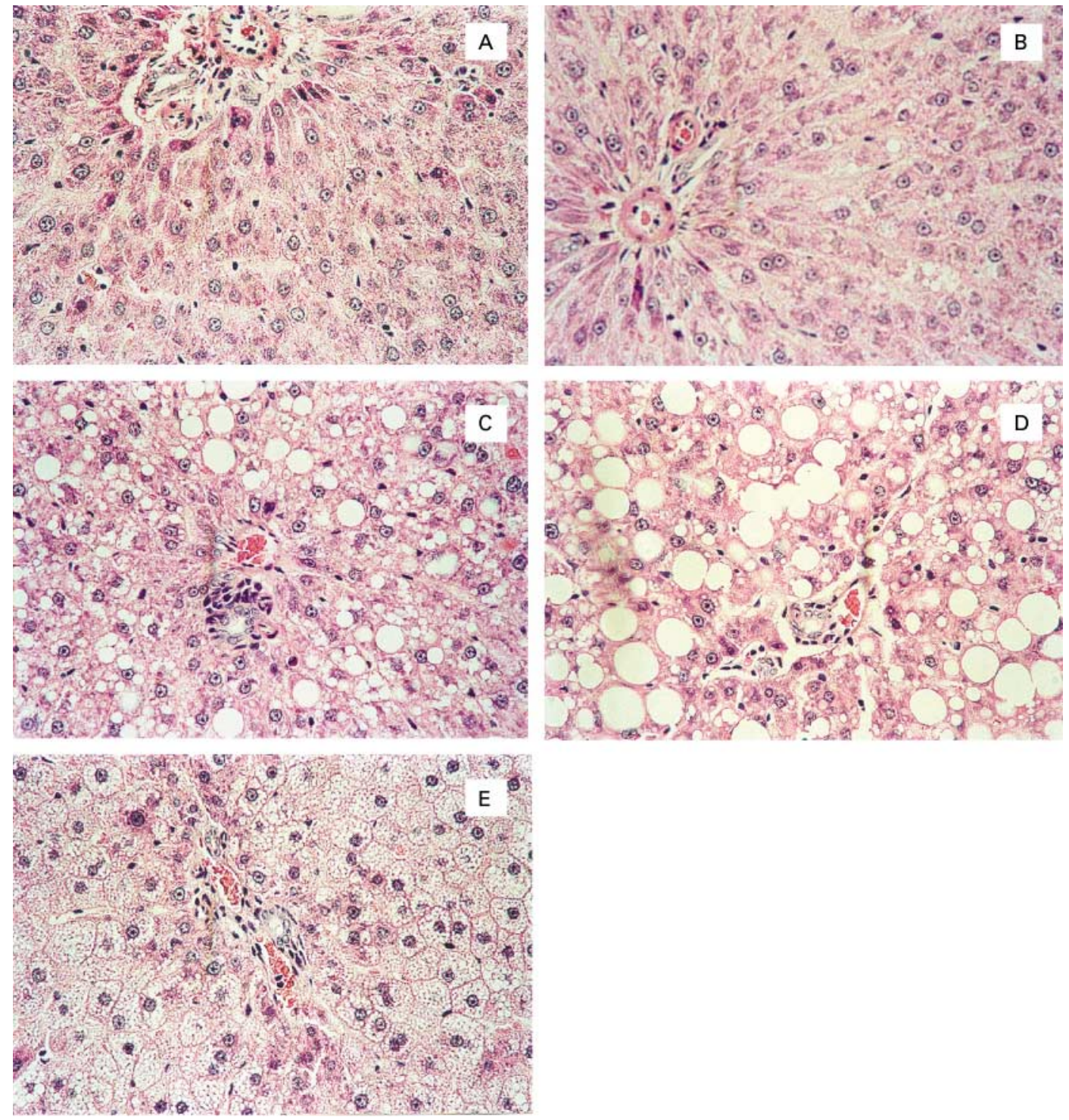

Fig. 3. Representative photomicrographs of liver sections of rats from experiments 2 and 3 (refer to the legends of Figs. 1 and 2 for details). Haematoxylin and eosin stain, original magnification, $\times 350$. (A) normal structure, $(B)$ mild steatosis, $(C)$ moderate steatosis, (D) severe macrovesicular and microvesicular steatosis, and (E) foamy degeneration.

and dissipate energy as heat via an up-regulation of the expression of uncoupling proteins (Armstrong \& Towle, 2001). To this end, it is relevant to point out that an ethyl acetate extract of BM (seed or flesh) has recently been shown to activate peroxisome proliferator-activated receptor $\alpha$ and up-regulate the expression of the acyl-CoA oxidase gene in H4IIEC3 hepatoma cells (Chao \& Huang, 2003).

In summary, BM supplementation elevates plasma catecholamines and serum FFA level but decreases hepatic and muscular TG content. The data suggest that chronic BM feeding leads to a general decrease in the TG content of the major organs. The latter phenomenon may be mediated in part by enhanced sympathetic activity, lipolysis and possibly lipid oxidation. The positive effects of BM on glycaemia and steatosis warrant further studies to isolate the bioactive ingredients and delineate the mechanisms of actions. In addition to its being a popular vegetable in many countries, the potential benefits of BM might be extended to blood glucose and weight control.

\section{Acknowledgement}

We thank Dr Irene Ng (Department of Pathology, The University of Hong Kong) for her assistance on hepatic steatosis grading. The excellent technical support of Ms Iris Tse and Ms Laureen Chan are also acknowledged. This work was supported by Research Grant Council of Hong Kong (HKU 7442/ 03M).

\section{References}

Ahmed I, Lakhani MS, Gillett M, John A \& Raza H (2001) Hypotriglyceridemic and hypocholesterolemic effects of anti-diabetic Momordica charantia (Karela) fruit extract in streptozotocin-induced diabetic rats. Diabetes Res Clin Pract 51, 155-161.

American Institute of Nutrition (1993) AIN-93 purified diets for laboratory rodents: final report of the American Institute of Nutrition ad hoc writing committee on the reformulation of the AIN-76A rodent diet. J Nutr 123, 1939-1951. 
Armstrong MB \& Towle HC (2001) Polyunsaturated fatty acids stimulate hepatic UCP-2 expression via a PPAR alpha-mediated pathway. Am J Physiol Endocrinol Metab 281, E1197-E1204.

Basch E, Gabardi S \& Ulbricht C (2003) Bitter melon (Momordica charantia): a review of efficacy and safety. Am J Health Syst Pharm 60, 356-359.

Boden G, Cheung P, Stein TP, Kresge K \& Mozzoli M (2002) FFA cause hepatic insulin resistance by inhibiting insulin suppression of glycogenolysis. Am J Physiol Endocrinol Metab 283, E12-E19.

Chao CY \& Huang CJ (2003) Bitter gourd (Momordica charantia) extract activates peroxisome proliferator-activated receptors and upregulates the expression of the acyl CoA oxidase gene in H4IIEC3 hepatoma cells. J Biomed Sci 10, 782-791.

Chen Q, Chan LLY \& Li ETS (2003) Bitter melon (Momordica charantia) reduces adiposity, lowers serum insulin and normalizes glucose tolerance in rats fed a high fat diet. $J$ Nutr 133, 1088-1093.

Danno H, Jincho Y, Budiyanto S, Furukawa Y \& Kimura S (1992) A simple enzymatic quantitative analysis of triglycerides in tissues. J Nutr Sci Vitaminol (Tokyo) 38, 517-521.

Dulloo AG, Seydoux J, Girardier L, Chantre P \& Vandermander J (2000) Green tea and thermogenesis: interactions between catechin-polyphenols, caffeine and sympathetic activity. Int $J$ Obes Relat Metab Disord 24, 252-258.

Folch J, Lees M \& Sloane Stanley GH (1957) A simple method for the isolation and purification of total lipids from animal tissues. $J$ Biol Chem 226, 497-509.

Forster CD \& Macdonald IA (1999) The assay of the catecholamine content of small volumes of human plasma. Biomed Chromatogr 13, 209-215.

Franch J, Knudsen J, Ellis BA, Pedersen PK, Cooney GJ \& Jensen J (2002) Acyl-CoA binding protein expression is fiber type-specific and elevated in muscles from the obese insulin-resistant Zucker rat. Diabetes 51, 449-454.

Friedenberg F, Pungpapong S, Zaeri N \& Braitman LE (2003) The impact of diabetes and obesity on liver histology in patients with hepatitis C. Diabetes Obes Metab 5, 150-155.

Grover JK \& Yadav SP (2004) Pharmacological actions and potential uses of Momordica charantia: a review. J Ethnopharmacol 93, 123-132.

Hegarty BD, Furler SM, Ye J, Cooney GJ \& Kraegen EW (2003) The role of intramuscular lipid in insulin resistance. Acta Physiol Scand 178, 373-383.

Hourigan LF, Macdonald GA, Purdie D, Whitehall VH, Shorthouse C, Clouston A \& Powell EE (1999) Fibrosis in chronic Lepatitis C correlates significantly with body mass index and steatosis. Hepatology 29, 1215-1219.

Jayasooriya AP, Sakono M, Yukizaki C, Kawano M, Yamamoto K \& Fukuda N (2000) Effects of Momordica charantia powder on serum glucose levels and various lipid parameters in rats fed with cholesterol-free and cholesterol-enriched diets. J Ethnopharmacol 72, 331-336.

Jensen MD (2003) Fate of fatty acids at rest and during exercise: regulatory mechanisms. Acta Physiol Scand 178, 385-390.

Kelley DE, Goodpaster BH \& Storlien L (2002) Muscle triglyceride and insulin resistance. Annu Rev Nutr 22, 325-346.

Khanna P, Jain SC, Panagariya A \& Dixit VP (1981) Hypoglycemic activity of polypeptide-P from a plant source. J Nat Prod 44, 648-655.

Marles R \& Farnsworth NR (1995) Antidiabetic plants and their active constituents. Phytomedicine 2, 137-189.
Meir P \& Yaniv Z (1985) An in vitro study on the effects of Momordica charantia on glucose uptake and glucose metabolism in rats. Planta Medica 33, 12-16.

Mokdad AH, Ford ES, Bowman BA, Dietz WH, Vinicor F, Bales VS \& Marks VS (2003) Prevalence of obesity, diabetes, and obesity-related health risk factors, 2001. JAMA 289, 76-79.

National Institutes of Health (1996) NIH Guide for the Care and Use of Laboratory Animals, 7th ed. Washington, DC: National Academy Press.

Ohnuki K, Haramizu S, Oki K, Ishihara K \& Fushiki T (2001) A single oral administration of conjugated linoleic acid enhanced energy metabolism in mice. Lipids 36, 583-587.

Peters SJ, Harris RA, Heigenhauser GJ \& Spriet LL (2001) Muscle fiber type comparison of PDH kinase activity and isoform expression in fed and fasted rats. Am J Physiol Regul Integr Comp Physiol 280, R661-R668.

Platel K, Shurpalekar KS \& Srinivasan K (1993) Influence of bitter gourd (Momordica charantia) on growth and blood constituents in Albino rats. Nahrung 37, 156-160.

Raman A \& Lau C (1996) Anti-diabetic properties and phytochemistry of Momordica charantia L (Cucurbitaceae). Phytomedicine 2, 349-362.

Robinson DS \& Speake BK (1989) Role of insulin and other hormones in the control of lipoprotein lipase activity. Biochem Soc Trans 171, 40-42.

Romsos DR \& Leveille GA (1974) Effect of diet on activity of enzymes involved in fatty acid and cholesterol synthesis. Adv Lipid Res 12, 97-146.

Shapiro K \& Gong WC (2002) Natural products used for diabetes. J Am Pharm Assoc (Wash) 42, 217-226.

Shibib BA, Khan LA \& Rahman R (1993) Hypoglycemic activity of Coccinia Indica and Momordica charantia in diabetic rats: depression of the hepatic gluconeogenic enzymes glucose-6-phosphatase and fructose-1,6-bisphosphase and elevation of both liver and red-cell shunt enzyme glucose-6-phosphate dehydrogenase. Biochem J 292, 267-270.

Singh N, Tyagi SD \& Agarwal SC (1989) Effects of long term feeding of acetone extract of Momordica charantia (whole fruit powder) on alloxan diabetic Albino rats. Indian J Physiol Pharmacol 33, 97-100.

Suzuki R, Arato S, Noguchi R, Miyashita K \& Tachikawa O (2001) Occurrence of conjugated linolenic acid in fresh and seed of bitter gourd. J Oleo Sci 50, 753-758.

Tsuzuki T, Igarashi M, Komai M \& Miyazawa T (2003) The metabolic conversion of 9,11,13-eleostearic acid (18:3) to 9,11-conjugated linoleic acid (18:2) in the rat. J Nutr Sci Vitaminol (Tokyo) 49, 195-200.

Virdi J, Sivakami S, Shahani S, Suthar AC, Banavalikar MM \& Biyani MK (2003) Antihyperglycemic effects of three extracts from Momordica charantia. J Ethnopharmacol 88, 107-111.

Yeh GY, Eisenberg DM, Kaptchuk TJ \& Phillips RS (2003) Systematic review of herbs and dietary supplements for glycemic control in diabetes. Diabetes Care 26, 1277-1294.

Yuwai KE, Rao KS, Kaluwin C, Jones GP \& Rivett DE (1991) Chemical composition of Momordica charantia L. fruits. J Agric Food Chem 39, $1762-1763$. 